\title{
The culture industry of the Russian Federation - integrated service centres: regional aspect
}

\author{
Natalya A. Malshina \\ Research Institute of goods circulation \\ and wholesale market conjuncture (ITKOR Institute) \\ Moscow, Russia \\ malsnataliya@yandex.ru
}

\begin{abstract}
Within the framework of the culture industry development of the Russian Federation, it is proposed to create an economic and mathematical model consisting of several elements: classification of cultural services; classification of the market of the culture industry; formation of a set of services for the culture industry (IC); state support, forms of public-private support (PPP); risk minimization; formation and practical implementation of cultural services programs within the integrated service complexes (Integrc). Economic support measures include the main elements: assessment of the potential for IR; the formation of information and analytical database (IABD) IC; the creation of economic and mathematical model of support for IC services; cost optimization (creation of Integrc IC); improving the efficiency of IC (economic, social, cultural).
\end{abstract}

Keywords-economic-mathematical model, services cultural industries, integrated service complex, organizational-economic mechanism

\section{INTRODUCTION}

In 1999, the UK first developed the concept of "creative industries". Today, they make up 5.4\% of the UK economy. They are part of the global market of $£ 2,250$ billion and one of the fastest growing sectors in the world.

In addition to traditional cultural value, "exchange value" (setting prices for cultural services on the market) and "functional value" (determined by their demand in real life), cultural services also possess "expressive value" - a criterion of their cultural significance. The fundamental criterion of the cultural industry, i.e. "creative industries", is the intellectual property right "as a catalyst for the transformation of creative activity into the creative industry " [4]. The original definition of creative industries formulated in 1998 in the UK by the government was as "industries that are based on individual creativity, skill and talent, and that contain opportunities to improve well-being and create jobs through the passage and use of intellectual property» [4]

Creative industries are recognized as the driving force behind innovation, economic growth, personal well-being, and community cohesion, but harnessing their potential can be a challenge. The development of digital technologies allows to open new opportunities for creative experience, breaking old models.

Based on statistical data, the development dynamics of the cultural industry in Russia shows a negative trend (table 1).

TABLE 1. Institutions of cultural and recreational type of all departments in the Russian Federation

\begin{tabular}{|l|r|r|r|r|r|}
\hline & \multicolumn{5}{|c|}{ Total } \\
\cline { 2 - 6 } & 2011 & 2012 & 2013 & 2014 & 2015 \\
\hline $\begin{array}{l}\text { Number of cultural and } \\
\text { recreational facilities }\end{array}$ & 44978 & 43712 & 42350 & 42068 & 40355 \\
\hline $\begin{array}{l}\text { The number of club } \\
\text { groups }\end{array}$ & 409169 & 408443 & 409978 & 413966 & 411403 \\
\hline $\begin{array}{l}\text { of the total - the } \\
\text { formation of Amateur } \\
\text { folk art }\end{array}$ & 273430 & 270555 & 270362 & 272737 & 270913 \\
\hline $\begin{array}{l}\text { The number of } \\
\text { participants in club } \\
\text { formations, thousand } \\
\text { people. }\end{array}$ & 6113,1 & 6055,1 & 6147,6 & 6227,1 & 6215,6 \\
\hline $\begin{array}{l}\text { of the total number of } \\
\text { participants in the club } \\
\text { groups - participating in } \\
\text { the formation of } \\
\text { Amateur folk art, } \\
\text { thousand people. }\end{array}$ & 3467,6 & 3448,6 & 3470,6 & 3545,3 & 3546,6 \\
\hline $\begin{array}{l}\text { The number of cultural } \\
\text { events - total, thousand } \\
\text { units. }\end{array}$ & 8226 & 8213 & 8189 & 8238 & 8145 \\
\hline $\begin{array}{l}\text { of the total number of } \\
\text { events - events on a paid } \\
\text { basis, thousand units. }\end{array}$ & 2615 & 2563 & 2546 & 2428 & 2335 \\
\hline $\begin{array}{l}\text { The number of visitors to } \\
\text { paid events, thousand } \\
\text { people. }\end{array}$ & 130957 & 125834 & 125032 & 120545 & 121957 \\
\hline Number of employees & 366608 & 369585 & 347199 & 324192 & 310694 \\
\hline $\begin{array}{l}\text { among them - specialists of } \\
\text { cultural and recreational } \\
\text { activities *) }\end{array}$ & 166079 & 170368 & 173341 & 181108 & 187971 \\
\hline
\end{tabular}

Regional differentiation of cultural institutions demonstrates a bright and obvious advantage in favor of the Volga Federal District (figure 1.). 

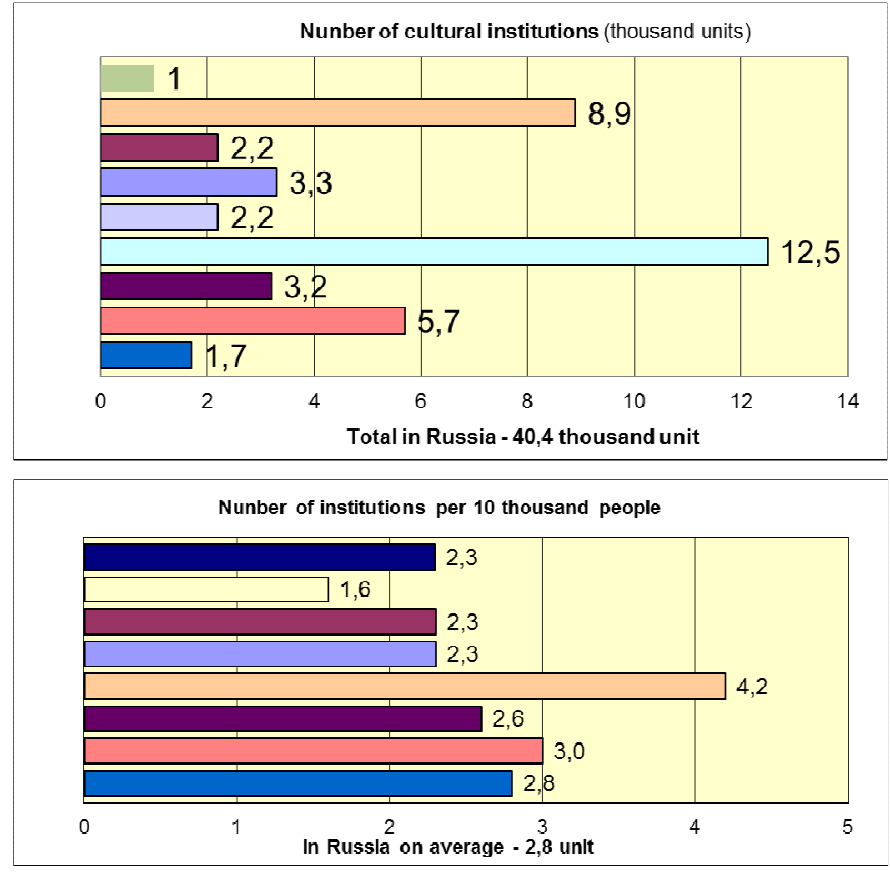

Fig. 1. Institutions of cultural and recreational type of all departments (regional aspect)

Financing of the cultural industry also demonstrates negative dynamics (figure 2).

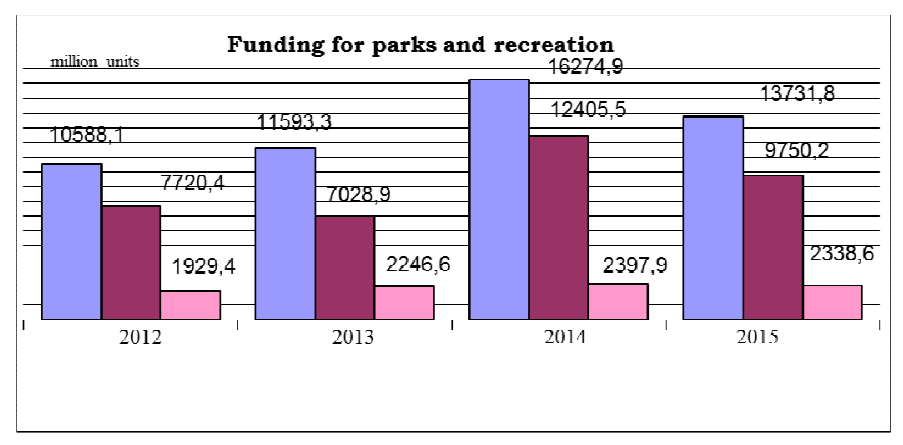

Fig. 2. Dynamics of financial resources for recreation parks in Russia

The relevance of the research and the expediency of the development of subjects lies in the fact that the development of the cultural industry is able to prevent unnecessary loss of time and various resources in the process of organizing the interaction of participants in the life cycle of the cultural industry of specific regions, taking into account their cultural and historical specifics.

The purpose and objectives of the study are determined by the problems of development of the system of management of services of the cultural industry.

The scientific novelty lies in the author's interpretation of the economic and mathematical model of the cultural industry development.

\section{MATERIALS AND Methods (MODEL)}

The model is understood as a formal and informal scheme of analysis, seeking to abstract from the complexities of the real world, but preserving the characteristics of the economic system. This makes it possible to understand the behavioral, organizational and technical relationships, which are unique for the discussed system. The model facilitates the explanation of economic phenomena and the development of economic forecasts.

In the generalized interpretation, the organizational and economic mechanism for supporting the cultural industry (OEM support IC) is a set of models, tools and methods that transform the initially set goals into concrete results. The modules of the mechanism, in our opinion, are their parts that determine the activities in relation to individual groups of microeconomic systems of the cultural industry $(\mathrm{I}=1, \ldots, \mathrm{k})$ and accordingly involve various forms of their support. Effective management of the process of support within the framework of the author's OEM support of the cultural industry is carried out using a block structure (blocks of methods, tools and impact models).

Then the OEM of support of the IC system of services is implemented as a regular, purposeful process of influence at all levels and at all stages of formation and movement of services on the factors and conditions ensuring achievement and maintenance of effective process of functioning of this sphere in the market. The formation of the organizational and economic mechanism to support cultural services, the choice of specific measures is determined by the decision of the development of a specific sector of the economy or the subject of the Russian Federation, in this case - the services of the cultural industry of the Saratov region.

Elements of the OEM blocks are a system of economic levers and incentives that allow bringing business process management into a state of effective functioning. The block of means of influence on the process of supporting the cultural industry consists of methodological and regulatory components.

The first group is a set of scientific methods, describing the process of supporting the system of services of the cultural industry with different aspects. These elements consist of fundamental theories and concepts that form the direction of development of the country and regions in the field of cultural services.

The second group of the OEM support IC normalizes and regulates the process of support and relations between the entities arising in the course of this process.

The process of supporting the service system of the cultural industry includes the information support (collection, transmission, processing and storage of information) of all stages of the process. The integration process is based on the coordination of information flows.

The unit of the impact on resource provision of OEM support determines the amount and movement of attracted financial resources, sources of income, evaluating their effectiveness and risk [1, p. 90], which suggests the presence of financial-economic components.

Management elements involve the regulation of relations among all the participants in the process of supporting the system of services of the cultural industry, through the 
definition of goals, objectives, functions and responsibilities of each participant in the process, the structure of interaction of all subjects.

Thus, the OEM support IC service system has a complex structure consisting of modules, blocks and elements. The modules are divided into directions in respect of individual groups of microeconomic systems in the culture industry. Blocks are components of the mechanism that override the means, models and methods of influence on the control system in various directions.

All elements of the OEM support IC service are closely interconnected and interact, being in a single system.

\section{RESULTS AND DISCUSSION}

The proposed model of the organizational and economic mechanism supporting the cultural industry presumes the integration into the existing economic structures both vertical and horizontal, which is aimed at the effective development of systems of state and regional economy, as well as subsystems at the level of municipalities and economic sectors.

Based on the principles of system analysis [2, p. 216] and research management systems, the solution for this problem is possible in the framework of the model of organizationaleconomic mechanism (OEM) support of cultural industries (IC). Within the framework of the activities of the IC support mechanism, several components are considered:

\section{1. classification of cultural services (author's);}

\section{2. classification of the IR market (author's);}

3. formation of a complex system of services of the cultural industry (KSSCI);

4. state support, forms of public-private support (PPP);

5. risk minimization;

6. the formation and implementation of programs services culture within integrated service systems (Integs).

Within the framework of the IC support OEM, economic activities include the main components:

\section{Assessing the potential of IC;}

2. The formation of information-analytical database (IABD) IC

3. Creation of economic and mathematical model of IC services support;

\section{Cost optimization (creating Integs IC);}

5. Improving the effectiveness of IC (economic, social, cultural).

Organizational activities within the OEM support IC are supposed to be carried out on the basis of the logistic approach of design unity, formation, functioning, implementation and management of the cultural services system on the basis of integration of individual parts of the system and include:

1. analysis of existing logistics support;
2. development and maintenance of operational documentation;

3. planning and management of logistics;

4. planning and organization of staff training;

5. formation of logistic infrastructure;

6. software and information and computing support;

7. monitoring of the technical condition;

8. unified logistics service system of the cultural industry.

The content, forms, methods of the program of logistic support of the cultural industry determine the process of implementation of logistics methodology leading to the optimization of organizational and economic activity of the cultural industry.

The problem of the formation and development of the complex of services of the cultural industry in the necessary framework of a systematic approach is solved by logistic methods and to ensure a balanced socio-economic development of the subjects of the cultural sphere, with the target setting of development - with a multiplicated total effect, improving the quality of life of all participants in the support process.

This model assumes a management methodology based on the synthesis of complex systemic and synergetic approaches. If a comprehensive and systematic approach determines the need to take into account all factors and their dynamics, the synergetic approach provides for the integration of elements that form the complex (integrated) potential of the cultural sphere. The approach to integrated capacity-building can be expressed by the following formula:

$$
\mathrm{CP}=\mathrm{f}\{\text { Isoc; Innp; Fp; Ekp; Етех; PRp; Рк }\},
$$

where: Isoc - social potential; Innp - innovative potential; $\mathrm{Fp}$ - financial potential; Ekp - economic potential; Eтеx - technical potential; PRp resource potential; Рк - cultural potential.

Each of their potentials requires evaluation (calculation and measurement) and further specific solutions for each subject of the sphere of culture.

This approach makes it possible to build systems of management of the culture industry, adapted to the changing needs of customers, forming effective management of resource flows and client flows, information services, insurance, pricing policy of the organization. As a result, there is a need to change the information model of relations between agents and contractors. The process of involvement of cultural organizations in the market economy requires the creation of new organizational and economic forms of logistics processes with the mandatory introduction of information technology. 


\section{CONCLUSION}

It is possible to conclude that the formation and management of the logistics system in integrated service systems (Integs) [3, p. 165] is necessary to conduct in parallel with the formation of the concentration and distribution service systems, including the processes of merging and downsizing of logistics flows of tangible and intangible resources.

As a result, the components of the process of providing cultural services using a logistic approach include:

1. Internal logistics: data collection, service, work with clients and personnel, etc.;

2. Marketing: promotion and sale of tickets and services, related products, advertising, information support, preparation of proposals, etc.;

3. External logistics: order processing, delivery of tools and personnel, preparation of reports;

4. Provision of services: direct contact between the consumer and the manufacturer of services as a result of the implementation of cultural services;

5. Post-realization service: customer support, customer feedback, complaints regulation, repair, etc.

Based on the potential of a particular support entity, the following types of support are selected: infrastructure development; management of resource flow processes; social capital; innovation climate; information support; supply (tools, advertising and area, etc.). these types of support can be provided by both state and non-state organizations and enterprises in various fields of the economy.

In this sense, services of the cultural industry are an innovative product and there is a qualitative relationship between the provision of services, the profit and the life cycle of cultural services and measures to support services of the cultural industry.

On the basis of the analysis it is possible to assert the necessity of development of the methodology of logistics of the sphere of social and cultural services by adapting this concept to the service specifics of a particular subject of the Russian Federation. The proposed methodological principles allow realizing the resource potential of the social and cultural service industry and improving the efficiency of its use, the quality of service to the population in the sphere of social and cultural services and ultimately ensure the competitiveness of enterprises in the sphere of social and cultural services.

Creating a new type of Autonomous organization of culture (Integrs) aims the combination of different forms of ownership and management within a single organization, thus attracting various sources of funding and improving the functioning and profitability. The financial independence of cultural organizations creates the preconditions for a combination of different activities, involvement of partner organizations of both Russian and foreign producers of services.

Currently, there is a need for new forms of interaction between government agencies, public organizations, nonprofit organizations and the business community. These support measures can lead to the creation of conditions for attracting investment, improving the competitiveness of cultural services, the efficiency of the cultural industry, modernization of the infrastructure of the Russian Federation, improving the quality of cultural services.

\section{References}

[1] Skorobogatova T. N. Logistic potential of an enterprise service [Logisticheskij potencial predprijatija servisa]/ Bulletin of the Russian economic University. G. V. Plekhanov (Moscow), 2006. No. 2. S. 86-93

[2] Optner S. the System analysis for solving business and industry issues[Sistemnyj analiz dlja reshenija delovyh i promyshlennyh problem]//Publishing house: Soviet radio. 1969.

[3] Malshina N. A. Model of perfection of management of flow processes in integrated service systems [Model of perfection of management of flow processes in integrated service systems]/ Proceedings of the Saratov University. New series. Series: Economics. Management. Right. 2014. Vol. 14. No. 1-2. P. 163-166.

[4] Newbigin, John. Introduction to the creative economy. M: "Creative economy", 2011. M: "Creative economy", $-256 \mathrm{p}$. 